\title{
Isoprenoid quinone composition of some marine Alteromonas, Marinomonas, Deleya, Pseudomonas and Shewanella species
}

\author{
Masayo Akagawa-Matsushita, ${ }^{1 *}$ Takashi Ito,${ }^{2} \dagger$ Yoko Katayama, ${ }^{2}$ Hiroshi Kuraishi ${ }^{2}$ \\ and KAZUHIDE YAMASATO ${ }^{1}$ \\ ${ }^{1}$ Institute of Applied Microbiology, The University of Tokyo, Bunkyo-ku, Tokyo 113, Japan \\ ${ }^{2}$ Faculty of Agriculture, Tokyo Noko University, 3-Saiwaicho, Fuchu, Tokyo 183, Japan
}

(Received 19 December 1991; revised 13 July 1992; accepted 15 July 1992)

\begin{abstract}
The isoprenoid quinone composition of 51 Gram-negative, aerobic, marine bacteria representing the genera Alteromonas, Marinomonas, Deleya, Pseudomonas and Shewanella was examined using high-performance liquid chromatography. Alteromonas and Marinomonas strains contained ubiquinone with eight isoprene units as their most abundant component, whilst ubiquinones with nine isoprene units predominated in Deleya and marine Pseudomonas strains. Members of the genus Shewanella contained both ubiquinones and menaquinones. The presence of two types of isoprenoid quinones in Shewanella is thought to be unique amongst Gram-negative, aerobic bacteria. In addition, methylmenaquinones were also found in Shewanella putrefaciens strains. The results demonstrate that the analysis of isoprenoid quinones offers a rapid and effective method of differentiating between some marine bacteria.
\end{abstract}

\section{Introduction}

Gram-negative, aerobic bacteria are commonly isolated from marine environments. The ecological and economic significance of these organisms has been reported (Yaphe \& Morgan, 1959; Yazawa et al., 1988; AkagawaMatsushita et al., 1991; Hayashida et al., 1991). However, identification of these organisms remains problematic due to limited taxonomic information. Problems with their identification are further compounded by the fact that aerobic bacteria inhabiting marine environments share essentially similar physiological and biochemical characters.

Amongst aerobic marine bacteria possessing polar flagella, members of the genera Alteromonas, Marinomonas and Shewanella have often been confused with each other and with members of the genus Pseudomonas

* Author for correspondence. Present address: Department of Chemistry, University of Occupational and Environmental Health, Yahatanishi-ku, Kitakyushu 807, Japan. Tel. 936031611 ext. 2243; fax 936025482 .

† Present address: Japan Collection of Microorganisms, RIKEN, Wako-shi, Saitama 351-01, Japan.

Abbreviations: Q, ubiquinone; MK, menaquinone; MMK, methylmenaquinone. because of their phenotypic similarity. The genus Alteromonas was created to encompass marine 'Pseudomonas-like' organisms which had a $\mathrm{G}+\mathrm{C}$ content of $38-50 \mathrm{~mol} \%$ (Baumann et al., 1972) and as such were very different from members of the genus Pseudomonas $(58-70 \mathrm{~mol} \%)$. Though this division resolved the conflict that one genus accommodates organisms with so wide a range of $\mathrm{G}+\mathrm{C}$ contents, it was still arbitrary as it was entirely based on $\mathrm{G}+\mathrm{C}$ content and each genus might remain heterogeneous. Subsequent to this, rRNA-DNA hybridization studies revealed that the genus Alteromonas was highly heterogeneous (Van Landschoot \& De Ley, 1983). Two species, $A$. communis and $A$. vagum were found to constitute a distinct rRNA branch and were transferred to the newly named genus Marinomonas (Van Landschoot \& De Ley, 1983). The genera Alteromonas and Marinomonas share many phenotypic similarities and can only be separated on the basis of a few characteristics.

Two further species of Alteromonas - A. putrefaciens, which had been transferred from Pseudomonas, and $A$. hanedai - were reassigned to the genus Shewanella, within the family Vibrionaceae, as a result of 5S rRNA sequencing (MacDonell \& Colwell, 1985). Further, A. colwelliana was subsequently assigned to this genus on the basis of studies utilizing similar methodologies (Coyne et al., 1989). 


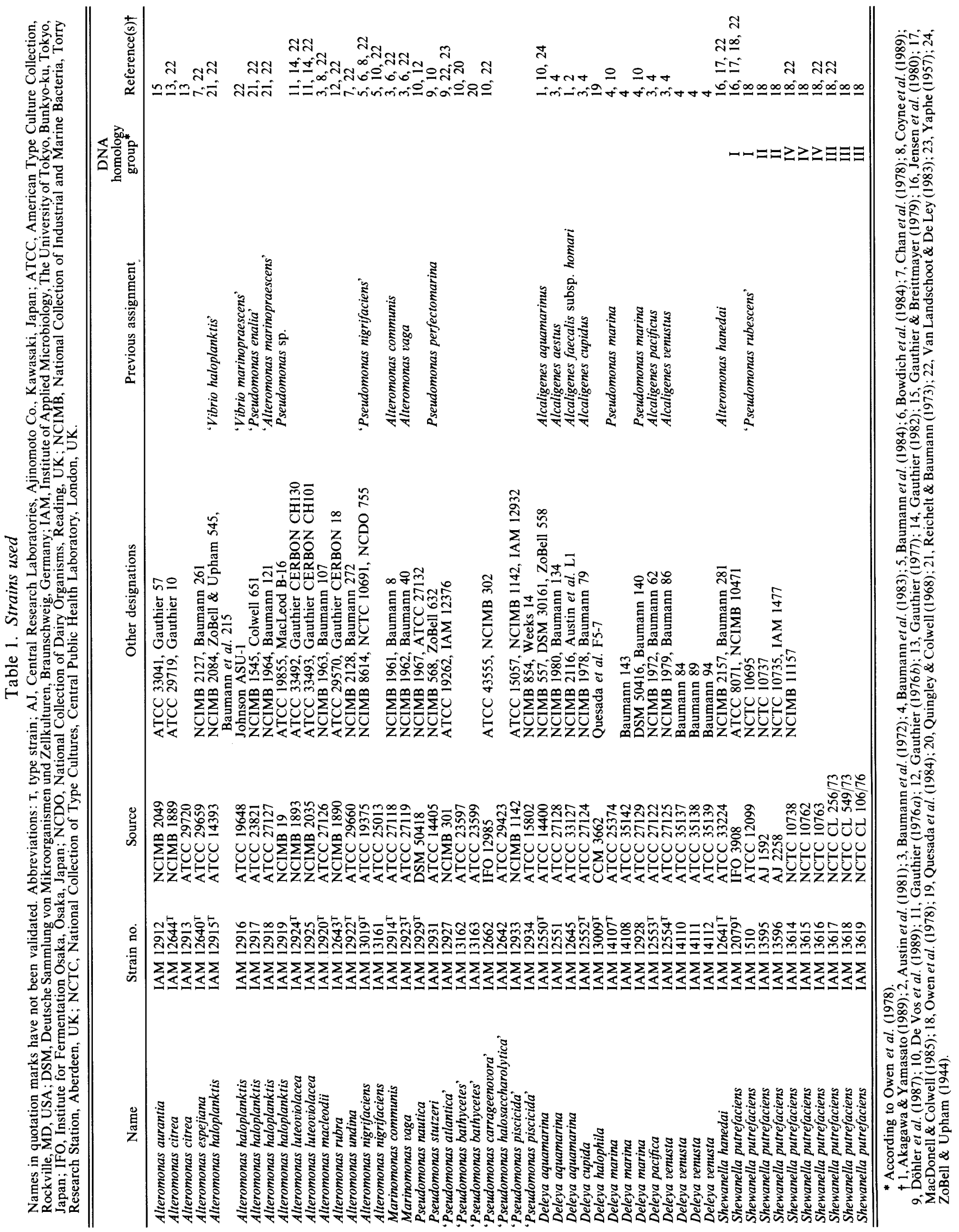


In a previous study (Baumann et al., 1972), four Gramnegative, aerobic species which possessed many features in common with marine Pseudomonas were assigned to the genus Alcaligenes, largely on the basis of peritrichous flagellation. Subsequent studies involving molecular techniques (Kersters \& De Ley, 1980), and comparative biochemical studies of the regulatory mechanism of aspartokinase (Baumann \& Baumann, 1974) and the catabolic pathway for D-fructose and D-glucose (Sawyer et al., 1977) revealed these organisms to be quite different from the genus Alcaligenes, and as such they were reassigned to the newly created genus Deleya (Baumann et al., 1983). The genus also contains a species originally assigned to the genus Pseudomonas, Deleya marina, which unlike the other species in this genus has polar flagella and was included largely on the basis of the phylogenetic implications of aspartokinase regulation (Baumann et al., 1983).

The genera discussed above have been created on the basis of advanced molecular and biochemical information; although there are phenotypic differences between these organisms, they are few in number. Therefore, there is a pressing need to uncover new phenotypic characteristics.

Chemotaxonomic analyses have proved of value in the characterization of a wide variety of prokaryotes (Goodfellow \& Minnikin, 1985). These characteristics are of increasing importance in the delineation of prokaryotic taxa (Murray et al., 1990); for example, they are employed in the descriptions of Aminobacter (Urakami et al., 1992), Sphingobacterium antarcticus (Shivaji et al., 1992) and Brachybacterium nesterenkovii (Gvozdyak et al., 1992). The value of isoprenoid quinone analyses has been discussed by Collins \& Jones (1981). In this study, the isoprenoid quinone composition of 51 strains of Gram-negative, aerobic, marine bacteria was analysed, and the results presented and discussed.

\section{Methods}

Organisms and growth condition. Strains, listed in Table 1, were grown in modified marine broth: peptone, $5.0 \mathrm{~g}$ (Kyokuto Pharmaceutical Industrial Co., Tokyo, Japan), yeast extract, $1.0 \mathrm{~g}$ (Oriental Yeast Co., Tokyo, Japan), $750 \mathrm{ml}$ of natural seawater and $250 \mathrm{ml}$ of distilled water. The final $\mathrm{pH}$ was adjusted to $\mathrm{pH} 7 \cdot 4$. Cultures were incubated for up to $15 \mathrm{~h}$ at $25^{\circ} \mathrm{C}$ with shaking at 120 r.p.m. Biomass was harvested and lyophilized at early stationary growth phase as described previously (Akagawa \& Yamasato, 1989).

Respiratory guinone analysis. Quinones were extracted with chloroform/methanol $(2: 1, v / v)$ from lyophilized cells and purified by preparative thin-layer chromatography on Merck Kieselgel $60 \mathrm{~F}_{254}$ $(20 \times 20 \mathrm{~cm}, 0 \cdot 25 \mathrm{~mm}$ thickness) using benzene as the developing solvent. Quinone spots were detected by UV irradiation. Spots were scraped from the TLC plates and recovered in acetone. High- performance liquid chromatography was used to determine the isoprenoid quinone composition. The apparatus comprised a Shimadzu liquid chromatograph LC-6A and a spectrophotometric detector SPD-2AM (Shimadzu) fitted with a reverse-phase type Cosmosil $5 C_{18}$ column (4.6 mm i.d. $\times 150 \mathrm{~mm}$, Nacalai Tesque Inc., Kyoto, Japan). The mobile phase used was a mixture of methanol and isopropyl ether $(3: 1, v / v)$, as described by Tamaoka et al. (1983). Ubiquinones and menaquinones were detected by monitoring at $275 \mathrm{~nm}$ and $270 \mathrm{~nm}$ respectively. Isoprenoid quinones were identified by comparison with known standards: phylloquinone, which was purchased from Wako Pure Chemical Industries (Osaka, Japan), and Q-6, Q-7, Q-8, Q-9, Q-10, MK-6, MK-7, MK-8, MK-9 and MK-10, which were a gift from S. Yamada (Tokyo Res. Lab., Eisai Co., Tokyo, Japan). The relative molar ratios of quinone homologues were determined by reference to the standard mixtures containing equimolar amounts of phylloquinone and Q-10.

Chemicals. All organic solvents were of analytical grade, with the exception of methanol which was of chromatographic grade (Nacalai Tesque Inc.).

\section{Results and Discussion}

The quinone compositions as determined by HPLC are shown in Table 2. Ubiquinones were the only type of isoprenoid quinones found in all strains, with the exception of members of the genus Shewanella.

Sixteen Alteromonas strains and two Marinomonas strains contained Q-8 as the most abundant component $(84-98 \%)$ accompanied by small amounts of Q-6, Q-7, Q-9 and Q-10. The genera Alteromonas and Marinomonas, which are not phylogenetically related, are almost indistinguishable using phenotypic characteristics (Van Landschoot \& De Ley, 1983). In this study, members of the genera could not be separated by quinone analysis (Table 2). Ubiquinone-8 has been found in species of Xanthomonas, Hydrogenophaga, Alcaligenes, Bordetella, Comamonas, Variovorax, Frateuria and Moraxella (Yamada et al., 1982; Fletcher et al., 1987; Yamada et al., 1969; Nishimura et al., 1986), and as such is widely distributed in the rRNA superfamilies I, II and III that correspond to the $\beta$ and $\gamma$ subdivisions in the class Proteobacteria. The lack of variation between these genera is therefore not surprising. However, Alteromonas and Marinomonas, which have often been confused with Pseudomonas, were clearly distinguished by isoprenoid quinone analysis. As reported previously (Akagawa \& Yamasato, 1989), all strains of the genus Deleya contained Q-9 as the most abundant quinone (90-98\%), accompanied by small amounts of Q-6, Q-7, Q-8 and Q-10. Deleya, which is the only taxon available for Gram-negative, aerobic, marine, peritrichous species, includes one polarly flagellated species, Deleya marina (Baumann et al., 1983). This species was concluded to be a member of the genus Deleya from a comparative study of the metabolic pathways of D-fructose (Sawyer et al., 1977) and immunological comparisons of certain 
Table 2. Isoprenoid quinone composition of the tested strains

Isoprenoid quinones were abbreviated as follows: Q-8, ubiquinone with eight isoprene units; MK-6, Menaquinone with six isoprene units; MMK-7, methylmenaquinone with seven isoprene units. Quinone compositions are presented as percentages. Where two types of quinone have been detected, values appearing outside parentheses are the percentages of ubiquinones or menaquinones alone, and values appearing within parentheses are the percentages of the total quinone profile.

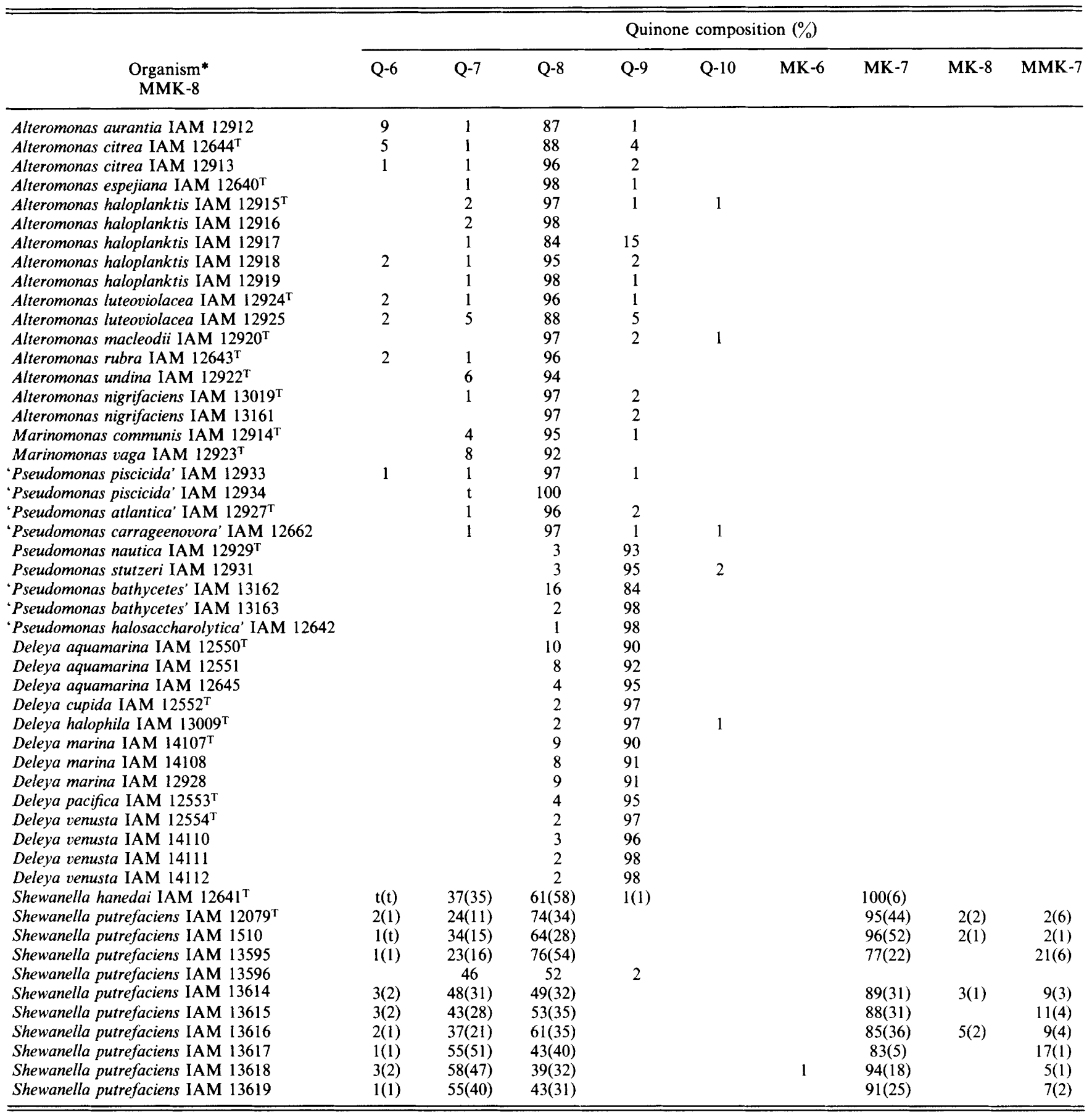

* $\mathrm{T}$, Type strain. 
enzymes (DeLong et al., 1984). The ubiquinone profile of Deleya marina shown in Table 2 is the same as those of other Deleya species that are peritrichously flagellated. The result is not contrary to the assignment of this species to genus Deleya. The quinone profile of Deleya species is similar to that of strains from the genus Halomonas (Franzmann \& Tindall, 1990). One of the most important taxonomic problems in the Halomonadaceae is the differentiation of Deleya and Halomonas (Franzmann \& Tindall, 1990). The results presented here highlight the phenotypic similarity of these two genera. Further differential chemotaxonomic characterization and systematic studies on Deleya, marine Pseudomonas and Halomonas species, including a larger number of isolates, are necessary.

Two marine Pseudomonas strains, Pseudomonas nautica IAM $12929^{\mathrm{T}}$ and Pseudomonas stutzeri IAM 12931 (formerly Pseudomonas perfectomarina) contained Q-9 as the most abundant quinone $(93 \%$ and $95 \%$, respectively) with small amounts of Q-8 and Q-10; as such they show similarities to some species of the Halomonadaceae and members of the genus Pseudomonas sensu stricto, i.e. rRNA homology group I (Franzmann \& Tindall, 1990; Yamada et al., 1982; Oyaizu \& Komagata, 1983). Marine Pseudomonas species are heterogeneous and none of them belong to Pseudomonas sensu stricto. Pseudomonas nautica has been assigned to the rRNA superfamily II by rRNA-DNA hybridization (De Vos et al., 1989), with no close relatives. However, the quinone profile for this strain is the same as those of authentic Pseudomonas (Yamada et al., 1982; Oyaizu \& Komagata, 1983). Pseudomonas stutzeri IAM 12931 was previously $P$. perfectomarina and was reassigned to this species on the basis of DNA-DNA hybridization studies (Döhler $e t$ al., 1987). Recently, Rossello et al. (1991) reported that Pseudomonas stutzeri contains several genomic groups and clearly, further investigations of this group are required. One terrestrial strain of Pseudomonas stutzeri IAM 1054 was reported to contain Q-9 (Yamada et al., 1982), in agreement with results for the marine strain studied here. The genomic heterogeneity uncovered by Rossello et al. (1991) was not confirmed here by isoprenoid quinone analysis.

Four misnamed Pseudomonas strains, 'Pseudomonas piscicida' IAM 12933 and IAM 12934, 'Pseudomonas atlantica' IAM 12927 and 'Pseudomonas carrageenovora' IAM 12662 all contained Q-8 as the most abundant component and showed the same ubiquinone profiles as those of Alteromonas and Marinomonas. These four strains should be reassigned to the genera Alteromonas or Marinomonas, in agreement with the findings of De Vos et al. (1989). The latter reported that Pseudomonas atlantica' IAM 12927 and 'Pseudomonas carrageenovora' IAM 12662 are not Pseudomonas and belong to the
Alteromonas haloplanktis rRNA branch on the basis of rRNA-DNA hybridization studies; the results presented here agree with their findings. Two strains of 'Pseudomonas bathycetes' and 'Pseudomonas halosaccharolytica' IAM 12462 were found to contain Q-9 as the major ubiquinone. These results demonstrate that 'Pseudomonas bathycetes' exhibits a profile similar to those of Deleya strains and supports the finding that 'Pseudomonas bathycetes' should be assigned to the genus Deleya or its relatives, as presented by De Vos et al. (1989). The quinone profile of 'Pseudomonas halosaccharolytica' IAM 12462 agreed with those of authentic Pseudomonas species (Yamada et al., 1982; Oyaizu \& Komagata, 1983); however, without further study it is difficult to determine the true identity of this strain.

As shown in Table 2, Shewanella strains contained both ubiquinones and menaquinones; in addition, methylmenaquinones were detected in most Shewanella putrefaciens strains with the exception of strain IAM 13596. The presence of both ubiquinones and menaquinones is a common feature of members of the family Enterobacteriaceae but has not been observed in any aerobic Gram-negative rod with the exception of Shewanella putrefaciens (Collins \& Jones, 1981; Moule \& Wilkinson, 1987). This may be an important differential characteristic among aerobic, motile marine bacteria. Further investigation of the quinone profiles of other Shewanella species, i.e. S. colwelliana, $S$. benthica and $S$. alga , is required. Amongst the strains of $S$. putrefaciens studied here, the quinones Q-7 and Q-8 were predominant components, followed by MK-7 and, with the exception of IAM 13596, MMK-7 was generally the fourth largest component. The presence of MMK in some strains of Shewanella putrefaciens has already been reported by Itoh et al. (1985) and Moule \& Wilkinson (1987); however, its taxonomic importance has not yet been recognized. Shewanella is heterogeneous with respect to DNA homology (Owen et al., 1978) and has been assigned to four homology groups. In the present study, we studied Shewanella putrefaciens strains from all four DNA-DNA homology groups presented by Owen $e t$ al. (1978), as indicated in Table 1. Owen's homology group I strains, IAM $12079^{\mathrm{T}}$ and IAM 1510 , contained a larger amount of MK-7, 44-52\% of the total quinones, as compared to the other strains, in which MK-7 did not exceed $36 \%$ of the total isoprenoid quinone content. In the homology group II strains, IAM 13595 and IAM 13596, the most abundant quinone was Q-8 followed by Q-7; in the homology group III strains, IAM 13617, IAM 13618 and IAM 13619, the most abundant quinone was Q-7 followed by Q-8. The homology group IV strains, IAM 13614, IAM 13615 and IAM 13616, contained almost equal amounts of Q-7 and Q-8. These differences in quinone profile between the four homology groups 
may indicate a subspecific structure in agreement with the work of Owen et al. (1978). The presence of MMKs in Shewanella putrefaciens may be an important characteristic in delineating this species; further studies are necessary.

In conclusion, determination of isoprenoid quinone profiles offers simple and clear criteria to distinguish the following three groups: (1) Alteromonas and Marinomonas; (2) Shewanella; and (3) marine Pseudomonas, Deleya and Halomonas. Its usefulness in primary grouping of natural isolates of aerobic, Gram-negative, motile, marine bacteria has been proved.

The authors thank Shigenori Yamada, Tokyo Research Laboratory, Eisai Co., for supplying known standards of quinones.

\section{References}

Akagawa, M. \& Yamasato, K. (1989). Synonymy of Alcaligenes aquamarinus, Alcaligenes faecalis subsp. homari, and Deleya aesta: Deleya aquamarina comb. nov. as the type species of the genus Deleya. International Journal of Systematic Bacteriology 39, 462-466.

Akagawa-Matsushita, M., Yamada, Y. \& Yamasato, K. (1991). Characterization and identification of a restriction enzyme producing marine bacterium Deleya marina IAM 14114. Bulletin of the Japan Federation for Culture Collections 7, 28-32.

Austin, B., Rodgers, C. R., Forns, J. M. \& Colwell, R. R. (1981). Alcaligenes faecalis subsp. homari subsp. nov., a new group of bacteria isolated from moribund lobsters. International Journal of Systematic Bacteriology 31, 72-76.

BaumanN, L. \& BaumanN, P. (1974). Regulation of aspartokinase activity in non-fermentative, marine eubacteria. Archives of Microbiology 95, 1-18.

Baumann, L., Baumann, P., Mandel, M. \& Allen, R. D. (1972). Taxonomy of aerobic marine eubacteria. Journal of Bacteriology 110, 402-429.

BaumanN, L., Bowditch, R. D. \& BaumanN, P. (1983). Description of Deleya gen. nov. created to accommodate the marine species Alcaligenes aestus, A. pacificus, A. cupidus, A. venustus, and Pseudomonas marina. International Journal of Systematic Bacteriology 33, 793-802.

Baumann, P., Baumann, L., Bowditch, R. D. \& Beaman, B. (1984). Taxonomy of Alteromonas: A. nigrifaciens sp. nov., nom. rev.; A. macleodii; and $A$. haloplanktis. International Journal of Systematic Bacteriology 34, 145-149.

Bowditch, R. D., BaumanN, L. \& BaumanN, P. (1984). Description of Oceanospirillum kriegii sp. nov. and $O$. jannaschii sp. nov. and assignment of two species of Alteromonas to this genus as $O$. commune comb. nov. and $O$. vagum comb. nov. Current Microbiology 10, 221-230.

Chan, K. Y., Baumann, L., Garza, M. M. \& Baumann, P. (1978). Two new species of Alteromonas: Alteromonas espejiana and Alteromonas undina. International Journal of Systematic Bacteriology 28, 217-222.

Collins, M. D. \& Jones, D. (1981). Distribution of isoprenoid quinone structural types in bacteria and their taxonomic implications. Microbiological Reviews 45, 316-354.

Coyne, V. E., Pillidge, C. J., Sledjeski, D. D., Hori, H., OrtizConde, B. A., Muir, D. G., Weiner, R. M. \& Colwell, R. R. (1989). Reclassification of Alteromonas colwelliana to the genus Shewanella by DNA-DNA hybridization, serology and $5 S$ ribosomal RNA sequence data. Systematic and Applied Microbiology 12, 275-279.

Delong, E. F., Baumann, L., Bowditch, R. D. \& Baumann, P. (1984). Evolutionary relationships of superoxide dismutases and glutamine synthetases from marine species of Alteromonas, Oceanospirillum, Pseudomonas and Deleya. Archives of Microbiology 138, 170-178.

De Vos, P., Van Landschoot, A., Segers, P., Tytgat, R., Gillis, M., Bauwens, M., Rossau, R., Pot, B., Kersters, K., Lizzaraga, P. \& DE LEY, J. (1989). Genotypic relationships and taxonomic localization of unclassified Pseudomonas-like strains by deoxyribonucleic acid : ribosomal ribonucleic acid hybridizations. International Journal of Systematic Bacteriology 39, 35-49.

DöHLER, K., HUSS, V. A. R. \& ZUMFT, W. G. (1987). Transfer of Pseudomonas perfectomarina Baumann, Bowditch, Baumann, and Beamann 1983 to Pseudomonas stutzeri (Lehmann and Neumann 1896) Sijderius 1946. International Journal of Systematic Bacteriology 37, 1-3.

Fletcher, M. T., Blackall, P. J. \& Doheny, C. M. (1987). A note on the isoprenoid quinone content of Bordetella avium and related species. Journal of Applied Bacteriology 62, 275-278.

FranzmanN, P. D. \& Tindall, B. J. (1990). A chemotaxonomic study of members of the family Halomonadaceae. Systematic and Applied Microbiology 13, 142-147.

GAUTHIER, M. J. (1976a). Morphological, physiological, and biochemical characteristics of some violet-pigmented bacteria isolated from seawater. Canadian Journal of Microbiology 22, 138-149.

GAUTHIER, M. J. (1976b). Alteromonas rubra sp. nov., a new marine antibiotic-producing bacterium. International Journal of Systematic Bacteriology 26, 459-466.

GaUthier, M. J. (1977). Alteromonas citrea, a new Gram-negative, yellow-pigmented species from seawater. International Journal of Systematic Bacteriology 27, 349-354.

GAUTHIER, M. J. (1982). Validation of the name Alteromonas luteoviolacea. International Journal of Systematic Bacteriology 32, 82-86.

Gauthier, M. J. \& BreitTMAYer, V. A. (1979). A new antibioticproducing bacterium from seawater: Alteromonas aurantia sp. nov. International Journal of Systematic Bacteriology 29, 366-372.

Goodfellow, M. \& MiNNIKIN, D. E. (1985). Introduction to chemosystematics. In Chemical Methods in Bacterial Systematics, pp. 1-16. Edited by M. Goodfellow \& D. E. Minnikin. London: Academic Press.

Gvozdyak, O. R., Nogina, T. M. \& Schumann, P. (1992). Taxonomic study of the genus Brachybacterium: Brachybacterium nesterenkovii sp. nov. International Journal of Systematic Bacteriology 42, 74-78.

Hayashida, S., TanaKa, S., Teramoto, Y., NanRI, N., Yoshino, S. \& FuruKawa, K. (1991). Isolation of anti-algal Pseudomonas stutzeri strains and their lethal activity for Chattonella antiqua. Agricultural and Biological Chemistry 55, 787-790.

IToh, T., Funabashi, H., Katayama-Fujimura, Y., Iwasaki, S. \& KURAISHI, H. (1985). Structure of methylmenaquinone-7 isolated from Alteromonas putrefaciens IAM 12079. Biochimica et Biophysica Acta 840, 51-55.

Jensen, M. J., Tebo, B. M., Baumann, P., Mandel, M. \& Nealson, K. H. (1980). Characterization of Alteromonas hanedai (sp. nov.), a nonfermentative luminous species of marine origin. Current Microbiology 3, 311-315.

KeRSTERS, K. \& DE LeY, J. (1980). Classification and identification of bacteria by electrophoresis of their proteins. In Microbiological Classification and Identification, pp. 273-297. Edited by M. Goodfellow \& A. G. Board. London: Academic Press.

MacDonell, M. T. \& Colwell, A. R. (1985). Phylogeny of the Vibrionaceae, and recommendation for two new genera, Listonella and Shewanella. Systematic and Applied Microbiology 6, 171-182.

Moule, A. L. \& Wilkinson, S. G. (1987). Polar lipids, fatty acids, and isoprenoid quinones of Alteromonas putrefaciens (Shewanella putrefaciens). Systematic and Applied Microbiology 9, 192-198.

Murray, R. G. E., Brenner, D. J., Colwell, R. R., De Vos, P., Goodfellow, M., Grimont, P. A. D., Pfennig, N., StackeBRANDT, E. \& ZaVarzin, G. A. (1990). Report of the Ad Hoc committee on approaches to taxonomy within the Proteobacteria. International Journal of Systematic bacteriology 40, 213-215.

Nishimura, Y., KanBe, K. \& IizUKA, H. (1986). Taxonomic studies of aerobic coccobacilli from seawater. Journal of General and Applied Microbiology 32, 1-11. 
OWen, R. J., Legros, R. M. \& LAPage, S. P. (1978). Base composition, size and sequence similarities of genome deoxyribonucleic acids from clinical isolates of Pseudomonas putrefaciens. Journal of General Microbiology 104, 127-138.

Oyaizu, H. \& Komagata, K. (1983). Grouping of Pseudomonas species on the basis of cellular fatty acid composition and the quinone system with special reference to the existence of 3-hydroxy fatty acids. Journal of General and Applied Microbiology 29, 17-40.

Quesada, E., Ventosa, A., Ruiz-BerRaQuero, F. \& RamosCormenzana, A. (1984). Deleya halophila, a new species of moderately halophilic bacteria. International Journal of Systematic Bacteriology 34, 287-292.

Quingley, M. M. \& Colwell, R. R. (1968). Proposal of a new species Pseudomonas bathycetes. International Journal of Systematic Bacteriology 18, 241-252.

Reichelt, J. L. \& Baumann, P. (1973). Change of the name Alteromonas marinopraescens (ZoBell and Upham) Baumann $e t$ al. to Alteromonas haloplanktis (ZoBell and Upham) comb. nov. and assignment of strain ATCC 23821 (Pseudomonas enalia) and strain c-A 1 of De Voe and Oginsky to this species. International Journal of Systematic Bacteriology 23, 438-441.

Rossello, R., Garcia-Valdes, E., Lalucat, J. \& Ursing, J. (1991). Genotypic and phenotypic diversity of Pseudomonas stutzeri. Systematic and Applied Microbiology 14, 150-157.

Sawyer, M. H., Baumann, P. \& Baumann, L. (1977). Pathways of $\mathrm{D}$-fructose and D-glucose catabolism in marine species of Alcaligenes, Pseudomonas marina, and Alteromonas communis. Archives of Microbiology 112, 169-172.

Shivaji, S., Ray, M. K., Rao, N. S., Saisree, L., JaGannadham, M. V., Kumer, G. S., RedDY, G. S. N. \& Bhargava, P. M. (1992). Sphingobacterium antarcticus sp. nov., a psychrotrophic bacterium from the soils of Schirmacher Oasis, Antarctica. International Journal of Systematic Bacteriology 42, 102-106.

Tamaoka, J., Katayama-Fujmura, Y. \& Kuraishi, H. (1983).
Analysis of bacterial menaquinone mixtures by high performance liquid chromatography. Journal of Applied Bacteriology 54, 31-36.

Urakami, T., Araki, H., Oyanagi, H., Suzuki, K. \& Komagata, K. (1992). Transfer of Pseudomonas aminovorans (den Dooren de Jong 1926) to Aminobacter gen. nov. as Aminobacter aminovorans comb. nova. and description of Aminobacter aganoensis sp. nov. and Aminobacter niigataensis sp. nov. International Journal of Systematic Bacteriology 42, 84-92.

VAN LANDSCHOOT, A. \& DE LEY, J. (1983). Intra- and intergeneric similarities of the rRNA cistrons of Alteromonas, Marinomonas (gen. nov.) and some other Gram-negative bacteria. Journal of General Microbiology 129, 3057-3074.

Yamada, Y., AIDA, K. \& UemURA, T. (1969). Enzymatic studies on the oxidation of sugar and sugar alcohol. V. Ubiquinone of acetic acid bacteria and its relation to classification of genera Gluconobacter and Acetobacter, especially of the so-called intermediate strains. Journal of General and Applied Microbiology 15, 181-196.

Yamada, Y., Takinami-Nakamura, H., Tahara, Y., Oyaizu, H. \& Komagata, K. (1982). The ubiquinone systems in the strains of Pseudomonas species. Journal of General and Applied Microbiology 28, 7-12.

YAPHE, W. (1957). The use of agarase from Pseudomonas atlantica in the identification of agar in marine algae (Rhodophyceae). Canadian Journal of Microbiology 3, 987-993.

YAPHE, W. \& Morgan, K. (1959). Enzymic hydrolysis of fucoidin by Pseudomonas atlantica and Pseudomonas carrageenovora. Nature, London 183, 761-762.

Yazawa, K., Araki, K., Okazaki, N., Watanabe, K., Ishikawa, C., INOUE, A. \& Kondo, K. (1988). Production of eicosapentaenoic acid by marine bacteria. Journal of Biochemistry 103, 5-7.

ZoBell, C. E. \& UphaM, H. C. (1944). A list of marine bacteria including descriptions of sixty new species. Bulletin of the Scripps Institution of Oceanography of the University of California 5, 239292. 